\title{
The Moderating Role of Attachment Styles on the Relationship between Alexithymia and Interpersonal Problems in an Iranian Population
}

\author{
Mohammad Ali Besharat ${ }^{1} \&$ Vahideh Shahidi ${ }^{2}$ \\ ${ }^{1}$ Department of Psychology, University of Tehran, Tehran, Iran \\ ${ }^{2}$ Department of Psychology, Wilfrid Laurier University, Waterloo, Ontario, Canada \\ Correspondence: Mohammad Ali Besharat, Department of Psychology, University of Tehran, P. O. Box \\ 14155-6456, Tehran, Iran. E-mail besharat@ut.ac.ir
}

Received: July 31, 2013

doi:10.5539/ijps.v5n4p60
Accepted: August 14, $2013 \quad$ Online Published: November 5, 2013

URL: http://dx.doi.org/10.5539/ijps.v5n4p60

\begin{abstract}
The moderating role of attachment styles on the relationship between alexithymia and interpersonal problems was assessed in the present study. Eight hundred and twenty nine Iranian general populations (372 men, 457 women) who were living in Tehran were involved in this study. The participants were asked to complete three questionnaires including Adult Attachment Inventory, Toronto Alexithymia Scale-20, and Inventory of Interpersonal Problems. Results showed a significant negative correlation between secure attachment style and interpersonal problems. Moreover, the results revealed that avoidant and ambivalent attachment styles as well as alexithymia had a significant positive correlation with interpersonal problems. Regression analysis indicated that attachment styles have a moderating role on the relationship between alexithymia and interpersonal problems. It can be concluded that the relationship between alexithymia and interpersonal problems is not a simple linear one. This is partly moderated by attachment styles.
\end{abstract}

Keywords: attachment, emotion regulation, information processing, interpersonal relation

\section{Introduction}

Alexithymia is a kind of mood deficiency that causes inability to regulate emotions as well as inability in cognitive processing (e.g., Taylor \& Bagby, 2000). Alexithymia has a polyhedral structure, which composed of a) difficulty in identifying feelings and distinguishing between feelings and physical anxiety related to emotional stimulation; b) difficulty describing feelings for others; c) limited visualizing that is specified in terms of poverty fantasies; d) objective cognitive style (non-visual), pragmatic and fact-based as well as externally oriented thinking (Sifneos, 2000; Taylor \& Bagby, 2000). Several studies have shown that people with alexithymia have difficulty in identifying others' emotion from their faces (e.g., Lane, Sechrest, Riedel, Weldon, Kaszniak et al., 1996). They also have limited capacity for sympathy with others' emotional conditions (e.g., McDougall, 1989). Do these kinds of emotional-communicational problems lead to interpersonal problems?

Interpersonal problems are those problems that are experienced with others and cause mental distress (e.g., Horowitz, 1994) or has association with these mental disturbances. Horowitz and colleagues (1988) analyzed the problems reported in clinical interviews. They found a set of interpersonal problems including difficulties in assertiveness, sociability, submissiveness, intimacy, responsibility, and controlling. In addition to the fact that people with alexithymia can not correctly identify the emotion from others' faces (e.g., Lane et al., 1996), they also are not able to always show sympathy with other individuals (e.g., McDougall, 1989). By considering these two facts, it can be hypothesized that these people have interpersonal problems. Although many studies support the relationship between alexithymia and some mental and physical disorders (e.g., Bagby, Taylor, \& Parker, 1994; Besharat, 2008), only one study (Besharat, 2009a) focused on the relation between alexithymia and interpersonal problems in a college student sample. Therefore, one of the objectives of the present study was to investigate this relation in a sample of Iranian general population.

One of the concerning issues to the researchers is the possible influence of psychological variables on the relationship between alexithymia and interpersonal problems. Therefore, the second aim of the present study was to investigate the moderating role of attachment styles on the relationship between alexithymia and interpersonal 
problems. It is important to examine this issue since some studies illustrated the link between attachment styles and alexithymia in adults (Besharat, 2010) as well as the influence that these styles have on interpersonal problems (Besharat, Golinejad, \& Ahmadi, 2003). Studies regarding attachment styles in children (e.g., Bowlby, 1969; Roque \& Veríssimo, 2011) showed that sensitivity and responsiveness of the first caregiver in response to the child's emotional state are the main factors in learning the distressing affects and relationships with others. Based on this evidence, there is the possibility that secure and insecure attachment styles may have the role in the relationship between interpersonal problems and alexithymia.

Emotions and the ability to recognize, describe and regulate emotions are largely influenced by interactions with the primary caregivers (Roque \& Veríssimo, 2011). Therefore, it can be assumed that emotional disorders may be related to attachment styles. Attachment styles are described as internal working models that influence the way children respond to separation from their attachment figures and reunion to them. Attachment styles are developed mainly based on the experiences of children-parents (caregivers) that remain stable at different stages of life (e.g., Rothbard \& Shaver, 1994). These styles may also affect the social interactions (Waters, Merrick, Treboux, Crowell, \& Albersheim, 2000). Based on Bowlby (1969), Ainsworth and colleagues (1978), described three different attachment styles in children including secure, avoidant, and ambivalent. These styles were confirmed for adults later (Hazan \& Shaver, 1987). The researchers interested in attachment, examined the effects of early experiences and their influence on children's future interactions. These effects were also confirmed in adulthood emotion regulation strategies (e.g., Dewitte, Houwer, Goubert, \& Buysse, 2010; Gresham \& Gullone, 2012). These studies have shown that individuals with secure attachment reported lower levels of negative emotions and make safer relationships with others. These people also show weakness in the ability to self-regulating anxiety, depression, and other negative emotions (e.g., Morley \& Moran, 2011).

Research conducted in the relationship between attachment styles and alexithymia have shown that the characteristics associated with alexithymia are more in insecure attachment styles (e.g., Besharat, 2010; Montebarocci, Codispoti, Baldaro, \& Rossi, 2004). Bernbaum and James (1994) studied the family factors associated with alexithymia. Results demonstrated that those children, who developed in insecure and anxious environments while the emotion detection is prevented, they do not learn the successful coping with emotional situations. Therefore, they become upset by experiencing an emotional situation. These difficulties and lack of appropriate mentor for expressing emotion may lead to anxiety and ambivalence (Bernbaum \& James, 1994). Besharat (2010) showed that insecurity in attachment relationship can predict defect and failure to identify and express emotions.

There are two main objectives of this study: a) Examining the relationship of alexithymia and interpersonal problems; b) Examining the moderating role of attachment styles on the relationship of alexithymia and interpersonal problems. By considering theoretical and research findings in this field, there are two hypotheses for this study: 1) There is a positive relationship between alexithymia and interpersonal problems; 2) Attachment styles have a moderating role on the relationship between alexithymia and interpersonal problems.

\section{Method}

\subsection{Participants and Procedure}

Participants of this study were 850 Iranian volunteers from general population who were living in Tehran. After the description of the research objectives, time requirements, response confidentiality, and the students' consent, Adult Attachment Inventory (AAI; Besharat, 2011), Farsi version of the Toronto Alexithymia Scale-20 (FTAS-20; Bagby et al., 1994; Besharat, 2007) and Inventory of Interpersonal Problems (Horowitz et al., 1988) were performed. To encourage participants and increase the accuracy of the test answering, they were asked to write their name and address information to circulate the results of the study if they agreed. The average time required to complete the questionnaire was 30 minutes. In order to control order effects and tiredness in participants, scales were presented in different sequences. Twenty-one individuals were excluded from statistical analysis due to incomplete responses. Hence, 829 individuals (372 men [mean age: 35.40, age range: 21-55, SD: 10.05] and 457 women [mean age: 33.16, age range: 20-52, SD: 7.74]) completed the whole study. Upon completion all participants were debriefed and thanked for their participation.

\subsection{Measures}

\subsubsection{Adult Attachment Inventory (AAI)}

The AAI is a 15-item inventory validated for the purpose of measuring attachment styles in Iranian populations (Besharat, 2011). The AAI is a self-report questionnaire and measures three attachment styles including secure, avoidant, and ambivalent on a five-point Likert scale ranging from 1 (very little) to 5 (very much). Minimum and 
maximum scores for the subscales of the AAI range from 5 to 25 , respectively. The Cronbach's alphas for a sample of 1480 participants ( 860 males, 620 females) were $.85, .84$, and .85 for secure, avoidant, and ambivalent attachment styles, respectively. These scores were different for women $(.86, .83$, and .84$)$ and men $(.84, .85$ and .86). These scores indicate good internal consistency for the AAI. Test-retest reliability of the AAI was calculated in a sample of 300 participants in two times with a four weeks interval and confirmed. Factor analysis identified that secure, avoidant, and ambivalent attachment styles were confirmed by the AAI (Besharat, 2011).

\subsubsection{Farsi version of the Toronto Alexithymia Scale (FTAS-20)}

Toronto Alexithymia Scale (TAS-20; Bagby et al., 1994) has 20 questions, and three subscale of difficulty identifying feelings, difficulty describing feeling, and externally oriented thinking on a five points Likret scale ranging from 1 (strongly disagree) to 5 (strongly agree). Participants' total score of the test consists of the summation of these three subscales. Several studies investigated and approved the psychometric properties of the TAS-20 (e.g., Taylor \& Bagby, 2000). Adequate psychometric properties of the FTAS-20 have reported for Iranian populations (Besharat, 2007).

\subsubsection{Inventory of Interpersonal Problems (IIP-60)}

The IIP is a 60-item questionnaire derived from the Inventory of Interpersonal Problems that has 127 items (Horowitz et al., 1988). The IIP-60 measures assertiveness, sociability, submissiveness, intimacy, responsibility, and controlling on a five-point Likert scale ranging from 0 (not at all) to 4 (extremely). This scale is composed of two parts: the first part is related to the first four subscales. The items begin with the words like "It' is hard for me to ...". In part two, sentences finish with the words like "...I do too much." In addition to the six subscales, an overall mean score of the interpersonal problems is calculated by adding all 60 items and dividing by the total number of items. In validation of a Farsi version of the IIP, the test was performed in two different groups: students (159 girls, 112 boys) and general population (490 women, 434 men). Adequate psychometric properties of the IIP-60 have reported for Iranian populations (Besharat, 2009b).

\section{Results}

Table 1 illustrates the statistical characteristics of participants according to attachment styles, alexithymia and interpersonal problems separately for men and women.

Table 1. Mean scores and standard deviations on each scale of the attachment, alexithymia, and interpersonal problems for men, women, and the total sample

\begin{tabular}{lllllll}
\hline Variable/Scale & Men & \multicolumn{3}{c}{ Women } & \multicolumn{3}{c}{ Total } \\
\cline { 2 - 7 } & $\mathrm{M}$ & $\mathrm{SD}$ & $\mathrm{M}$ & $\mathrm{SD}$ & $\mathrm{M}$ & $\mathrm{SD}$ \\
\hline Secure attachment style & 16.17 & 4.12 & 15.28 & 3.60 & 15.68 & 3.87 \\
Avoidant attachment style & 12.89 & 4.22 & 13.24 & 4.41 & 13.05 & 4.31 \\
Ambivalent attachment style & 10.93 & 3.48 & 11.46 & 3.72 & 11.23 & 3.62 \\
Alexithymia & 44.59 & 14.09 & 45.96 & 11.45 & 45.35 & 12.71 \\
Interpersonal problems & 2.03 & .61 & 2.27 & .72 & 2.16 & .68 \\
\hline
\end{tabular}

Pearson correlation test results are shown in Table 2. Based on this data, there is a significant negative correlation between secure attachment style and interpersonal problems. Insecure attachment styles and alexithymia show significant positive correlations with interpersonal problems.

Table 2. Zero order correlations between attachment styles, alexithymia, and interpersonal problems for the total sample

\begin{tabular}{lllll}
\hline Variable & 1 & 2 & 3 & 4 \\
\hline 1. Secure attachment style & 1 & & & \\
2. Avoidant attachment style & -.81 & 1 & & \\
3. Ambivalent attachment style & -.72 & .66 & 1 & \\
4. Alexithymia & -.81 & .76 & .61 & 1 \\
5. Interpersonal problems & -.42 & .39 & .37 & .38 \\
\hline
\end{tabular}

Note. All $p$ values $<.001$ 
Moderated regression analysis was performed to investigate the moderating role of attachment styles in the relationship between alexithymia and interpersonal problems (Table 3). Regression model 1 shows that the relationship between secure attachment and alexithymia is .42 . This can explain .17 percent of interpersonal problems variance significantly. The second regression model shows the relationship between predictor variables of alexithymia and secure attachment style after interring moderating effect of secure attachment style in the equation. Comparing Models 1 and 2 indicate that secure attachment style increase the $\mathrm{R}^{2}$ significantly by .04 percent $\left(\triangle \mathrm{R}^{2}=.04, \Delta \mathrm{F}=36.89, p=.001\right)$. Model 2 shows that .04 percent of the observed variance in scores on the interpersonal problems is explained by the moderating role of secure attachment style.

Table 3. Regression analysis to determine the moderating role of secure attachment style on the relationship between alexithymia and interpersonal problems

\begin{tabular}{lllllll}
\hline Models & $\mathrm{R}$ & $\mathrm{R}^{2}$ & Adjusted $\mathrm{R}^{2}$ & $\Delta \mathrm{R}^{2}$ & $\Delta \mathrm{F}$ & $p$ \\
\hline 1 & .42 & .17 & .17 & .17 & 87.12 & .001 \\
2 & .46 & .21 & .21 & .04 & 36.89 & .001 \\
\hline
\end{tabular}

Model I. Predictor variables: alexithymia and secure attachment style

Model II. Predictor variables: alexithymia, secure attachment style, moderating role of secure attachment style

Standardized and non-standardized regression coefficients are presented in Table 4. These coefficients indicate that the moderating effect of secure attachment $(\beta=-.254, t=-6.07, p=.001)$ can significantly explain variance of interpersonal problems.

Table 4. Standardized and non-standardized regression analysis with the moderating role of secure attachment style in the relationship of alexithymia and interpersonal problems

\begin{tabular}{llllll}
\hline Models & $\mathrm{B}$ & $\mathrm{SE}$ & $\beta$ & $t$ & $p$ \\
\hline Alexithymia & .022 & .004 & .402 & 5.50 & .001 \\
Secure attachment style & -.024 & .011 & -.134 & -2.11 & .034 \\
Moderating effect of secure attachment & -.001 & .001 & -.254 & -6.07 & .001 \\
\hline
\end{tabular}

The same regression analysis was performed to investigate the moderating role of avoidant attachment style in the relationship between alexithymia and interpersonal problems (Table 5). Regression model 1 shows that the relationship between avoidant attachment and alexithymia is .41 . This can explain .17 percent of interpersonal problems variance significantly. The second regression model shows the relationship between predictor variables of alexithymia and avoidant attachment style after interring moderating effect of avoidant attachment style in the equation. Comparing Models 1 and 2 indicate that avoidant attachment style increase the $\mathrm{R}^{2}$ significantly by .03 percent $\left(\triangle \mathrm{R}^{2}=.03, \Delta \mathrm{F}=29.68, p=.002\right)$. Model 2 shows that .03 percent of the observed variance in scores on the interpersonal problems is explained by the moderating role of avoidant attachment style.

Table 5. Regression analysis to determine the moderating role of avoidant attachment style on the relationship between alexithymia and interpersonal problems

\begin{tabular}{lllllll}
\hline Models & $\mathrm{R}$ & $\mathrm{R}^{2}$ & Adjusted $\mathrm{R}^{2}$ & $\Delta \mathrm{R}^{2}$ & $\Delta \mathrm{F}$ & $p$ \\
\hline 1 & .41 & .17 & .17 & .17 & 82.39 & .001 \\
2 & .44 & .20 & .20 & .03 & 9.68 & .002 \\
\hline
\end{tabular}

Model I. Predictor variables: alexithymia and avoidant attachment style

Model II. Predictor variables: alexithymia, avoidant attachment style, moderating role of avoidant attachment style 
Standardized and non-standardized regression coefficients are presented in Table 6 . These coefficients indicate that the moderating effect of avoidant attachment $(\beta=.170, t=3.11, p=.002)$ can significantly explain variance of interpersonal problems.

Table 6. Standardized and non-standardized regression analysis with the moderating role of avoidant attachment style in the relationship of alexithymia and interpersonal problems

\begin{tabular}{llllll}
\hline Models & B & SE & $\beta$ & $t$ & $p$ \\
\hline Alexithymia & .007 & .003 & .121 & 2.25 & .025 \\
Avoidant attachment style & .026 & .009 & .165 & 3.04 & .002 \\
Moderating effect of avoidant attachment & .001 & .001 & .170 & 3.11 & .002 \\
\hline
\end{tabular}

Regression analysis was performed to investigate the moderating role of ambivalent attachment style in the relationship between alexithymia and interpersonal problems (Table 7). Regression model 1 shows that the relationship between ambivalent attachment and alexithymia is .42. This can explain .17 percent of interpersonal problems variance significantly. The second regression model shows the relationship between predictor variables of alexithymia and ambivalent attachment style after interring moderating effect of ambivalent attachment style in the equation. Comparing Models 1 and 2 indicate that ambivalent attachment style increase the $\mathrm{R}^{2}$ significantly by .06 percent $\left(\triangle \mathrm{R}^{2}=.06, \Delta \mathrm{F}=60.79, p=.002\right)$. Model 2 shows that .06 percent of the observed variance in scores on the interpersonal problems is explained by the moderating role of ambivalent attachment style.

Table 7. Regression analysis to determine the moderating role of ambivalent attachment style on the relationship between alexithymia and interpersonal problems

\begin{tabular}{lllllll}
\hline Models & $\mathrm{R}$ & $\mathrm{R}^{2}$ & Adjusted $\mathrm{R}^{2}$ & $\Delta \mathrm{R}^{2}$ & $\Delta \mathrm{F}$ & $p$ \\
\hline 1 & .42 & .17 & .17 & .17 & 86.52 & .001 \\
2 & .48 & .23 & .23 & .06 & 60.79 & .002 \\
\hline
\end{tabular}

Model I. Predictor variables: alexithymia and ambivalent attachment style

Model II. Predictor variables: alexithymia, ambivalent attachment style, moderating role of ambivalent attachment style

Standardized and non-standardized regression coefficients are presented in Table 8 . These coefficients indicate that the moderating effect of ambivalent attachment $(\beta=.791, t=7.80, p=.001)$ can significantly explain variance of interpersonal problems.

Table 8. Standardized and non-standardized regression analysis with the moderating role of ambivalent attachment style in the relationship of alexithymia and interpersonal problems

\begin{tabular}{llllll}
\hline Models & $\mathrm{B}$ & $\mathrm{SE}$ & $\beta$ & $t$ & $p$ \\
\hline Alexithymia & -.006 & .003 & -.104 & -1.78 & .075 \\
Ambivalent attachment style & -.051 & .014 & -.269 & -3.62 & .001 \\
Moderating effect of ambivalent attachment & .002 & .001 & .791 & 7.80 & .001 \\
\hline
\end{tabular}

\section{Discussion}

The present study was aimed to examine the relationship of alexithymia and attachment styles with interpersonal problems. Afterwards, the moderating role of attachment styles on the relationship between alexithymia and interpersonal problems was investigated. The results showed that alexithymia, avoidant and ambivalent attachment styles had a significant positive correlation with interpersonal problems; whereas, secure attachment style had a significant negative correlation with interpersonal problems. Firstly, the data analysis showed that 
when alexithymia increased levels of interpersonal problems increased as well. Secondly, attachment styles had a moderating role on the relationship between alexithymia and interpersonal problems. Confirming the research hypotheses, the results of the present study are in line with the findings of previous research (e.g., Besharat, 2009a, 2010; Montebarocci et al., 2004). These results could be clarified by several possible explanations.

Studies have shown that people with alexithymia have difficulty in identifying the emotion of others from their face (e.g., Lane et al., 1996). Recognizing emotions play an important role on interpersonal relations. Failure to recognize the right emotions confront the person with many problems in interpersonal relationships. For example, sociability and intimate relationships with others require the ability to understand their own emotions and others. Inability to recognize emotions leads to interpersonal problems in these areas. Accordingly, it could be considered that alexithymia might increase interpersonal problems through deficiency and inability to recognize emotions.

People with alexithymia have limited capacity for sympathy with others' and their emotional states (e.g., McDougall, 1989). Limitation and disability for sympathy and empathy with others makes interpersonal relationships difficult, especially in the fields of sociability and intimacy. Accordingly, there is a possibility that alexithymia might increase interpersonal problems through limited capacity for sympathy and empathy with others.

Alexithymia is described as a difficulty in emotional self-regulation and inability in cognitive processing of emotional information (Taylor \& Bagby, 2000). When there is an inability in cognitive processing of emotional information, people may feel frustrated and distressed. This disability disturbs the organization of emotions and cognitions. At a level of social interaction, this impairment can lead to individual's interpersonal problems. Management and regulation of emotions may also be disrupted in both personal and interpersonal behavior. Therefore, this disruption may explain some part of interpersonal problems. According to these explanations, interpersonal problems may be directly affected by impaired cognitive processing of emotional information, or through mental health problems.

The results of the present study showed that attachment styles may have a moderating role on the relationship between alexithymia and interpersonal problems. Attachment styles influence the emotion regulation strategies (e.g., Dewitte, Houwer, Goubert, \& Buysse, 2010; Gresham \& Gullone, 2012). People with secure attachment, because of having responsive and sensitive parents to their emotional state in childhood, have learned how to regulate their emotions and to communicate with others (e.g., Bowlby, 1969; Roque \& Veríssimo, 2011). This situation is completely opposite in insecure attached people. The higher levels of insecure attachment, the more difficulty in processing and regulating emotions in interpersonal relationships. On the other hand, defects and failures in emotion regulation is one of the main features of alexithymia. Emotional development and cognitive skills of emotional regulation are impaired in people with alexithymia (Taylor \& Bagby, 2000). As a result, by considering the impact of attachment on emotion regulation, by higher rate of insecure attachment in people with alexithymia, the individuals' ability will be less in emotion regulation and consequently the interpersonal problems increases as well.

People with avoidant attachment due to lack of trust to others usually keep away and do not interact well with others (Bartholomew \& Horowitz, 1991). Similarly, people with alexithymia have a poor and limited social networks, various interpersonal problems, and do not like to become close to others (Besharat, 2009a; Montebarocci et al., 2004). Distrust and distance from others is an important factor in causing communication problems. As a result, the person with alexithymia and higher levels of insecurity, has lower willingness to communicate with others. Therefore, avoidant attachment style can increase the effect of alexithymia on interpersonal problems.

People with avoidant attachment styles would avoid the communication. These people would less seek support in distress situations. They would also show less reaction to others' distress situation. In other words, understanding and comprehending others' feeling have lower priority for these people. Empathy and sympathy of these people is low. One important aspect of alexithymia is difficulty in identifying others' emotions, and thus empathy with others becomes difficult. Findings show that empathy is an important factor affecting interpersonal relationships (e.g., Wilkie, Ferree, \& Ratcliff, 1998). Attachment insecurity due to its negative effect on empathy (Besharat, Khodabakhsh, Farahani, \& Rezazadeh, 2011), can increase interpersonal problems.

One of the important factors in intimacy and satisfaction in the relationships is expressing the emotions and feelings (Kathryn \& Timmerman, 2003). People with avoidant attachment, have difficulty in interpersonal relationships, and they have limited ability to create intimacy (Kathryn \& Timmerman, 2003). One of the most important factors that brings intimacy into the relationship is self-expression, means expression of emotions for 
others (Sanderson \& Evans, 2001). Difficulty to express emotions and understanding the emotions of others is one of the characteristics of alexithymia. Accordingly, there is a possibility that insecure attachment may exacerbate in emotional self-expression. As a result, the ability to express emotions in interpersonal relationships reduced.

In summary, the results of the present study showed that there is a correlation between alexithymia and interpersonal problems, and attachment styles play moderating role in this relationship. Implications of this research can be both theoretical and practical stated as follows: at the theoretical level, the results of this research can help to understand better the determinants of interpersonal relationship problems. The results of the present study confirm previous research and theories concerning the relationship of alexithymia, attachment styles, and interpersonal problems. These results could raise new questions and hypotheses. Examples of these questions include: What is the effect of each variable of alexithymia and interpersonal problems on each other? Do interpersonal problems have a determining role on alexithymia? Does the effect of alexithymia on different aspect of interpersonal problems is same or different? What other variables can have a moderating role on the relationship between alexithymia and interpersonal problems? The answer to each of these questions and related hypotheses require an independent research, which is suggested to interested researchers. On the practical and particularly clinical level, providing emotional and communication skills educational programs could be a good example of this study contribution. Moreover, some appropriate and effective strategies can be taught to people. These programs can be entered in the field of interventional treatment plans based on the cognitive processing of emotional information and the regulation of emotion. They also could increase these treatments' effectiveness. Treatment programs based on interpersonal problems can also use the empirical findings of the present study.

This study has some limitations that most important of them are as follows. Correlational research design does not allow to draw conclusions about the directions of causality between alexithymia, attachment, and interpersonal problems. The sample of this study is consisted of some volunteers from general population and could not be easily generalized to other populations. To evaluate the relationship between alexithymia and interpersonal problems, it is important to examine the role of moderator variables such as coping strategies and defense mechanisms. Additionally, it is recommended for better understanding the effects of alexithymia on interpersonal problems, the relationship between these two variables must be examined in clinical samples including examples of psychological disorder, personality disorders, and family problems.

\section{Acknowledgments}

The authors would like to acknowledge the financial support of University of Tehran for this research under grant number 5106003/1/53.

\section{References}

Ainsworth, M. D. S., Blehar, M. C., Waters, E., \& Wall, S. (1978). Patterns of attachment: A psychological study of the strange situation. Hillsdale, NJ: Erlbaum.

Bagby, R. M., Taylor, G. J., \& Parker, J. D. A. (1994). The twenty-item Toronto Alexithymia Scale: II. Convergent, discriminant, and concurrent validity. Journal of Psychosomatic Research, 38, 33-40. http://dx.doi.org/10.1016/0022-3999(94)90006-X

Bartholomew, K., \& Horowitz, L. (1991). Attachment styles among young adults: A test of a four-category model. Journal of Personality and Social Psychology, 61, 226-244. http://dx.doi.org/10.1037/0022-3514.61.2.226

Bernbaum, H., \& James, T. (1994). Correlates and retrospectively reported antecedents of alexithymia. Psychosomatic Medicine, 56, 353-359.

Besharat, M. A. (2007). Reliability and factorial validity of Farsi version of the Toronto Alexithymia Scale with a sample of Iranian students. Psychological Reports, 101, 209-220.

Besharat, M. A. (2008). Relations between alexithymia, anxiety, depression, psychological distress, and psychological well-being. Journal of Psychology, 10, 17-40. [Farsi]

Besharat, M. A. (2009a). Alexithymia and interpersonal problems. Studies in Education \& Psychology, 1, 129-145. [Farsi]

Besharat, M. A. (2009b). Reliability, validity, and factorial analysis of a short form of the Inventory of Interpersonal Problems in an Iranian population. Contemporary Psychology, 8, 25-36. [Farsi]

Besharat, M. A. (2010). Attachment styles and alexithymia. Psychological Research, 24, 63-80. [Farsi] 
Besharat, M. A. (2011). Development and validation of Adult Attachment Inventory. Procedia - Social and Behavioral Sciences, 30, 475-479. http://dx.doi.org/10.1016/j.sbspro.2011.10.093

Besharat, M. A., Golinejad, M., \& Ahmadi, A. A. (2003). An investigation of the relationship between attachment styles and interpersonal problems. Quarterly Journal of Andisheh va Raftar, 32, 74-78.

Besharat, M. A., Khodabaksh, M. R., Farahani, H., \& Rezazadeh, M. R. (2011). Mediating role of narcissism on the relationship between empathy and quality of interpersonal relationships. Quarterly Journal of Applied Psychology, 17, 7-23. [Farsi]

Bowlby, J. (1969). Attachment and loss: Vol. I. Attachment. New York: Basic Books.

Dewitte, M., Houwer, J. D., Goubert, L., \& Buysse, A. (2010). A multi-modal approach to the study of $\begin{array}{lllll}\text { attachment-related } & \text { distress. } & \text { Biological } & \text { Psychology, } & 85,\end{array}$ http://dx.doi.org/10.1016/j.biopsycho.2010.06.006

Gresham, D., \& Gullone, E. (2012). Emotion regulation strategy use in children and adolescents: The explanatory roles of personality and attachment. Personality and Individual Differences, 52, 616-621. http://dx.doi.org/10.1016/j.paid.2011.12.016

Hazan, C., \& Shaver, P. R. (1987). Romantic love conceptualized as an attachment process. Journal of Personality and Social Psychology, 52, 511-524. http://dx.doi.org/10.1037/0022-3514.52.3.511

Horowitz, L. M. (1994). Pschemas, psychopathology, and psychotherapy research. Psychotherapy Research, 4, 1-19. http://dx.doi.org/10.1080/10503309412331333862

Horowitz, L. M., Rosenberg, S. E., Baer, B. A., Ureno, G., \& Villasenor, V. S. (1988). Inventory of Interpersonal Problems: psychometric properties and clinical applications. Journal of Consulting and Clinical Psychology, 56, 885-892. http://dx.doi.org/10.1037/0022-006X.56.6.885

Kathryn, D., \& Timmerman, L. (2003). Accomplishing romantic relationship. In J. O. Greene, \& B. R. Burleson (Eds.), Handbook of communication and social interaction skills (pp. 685-690). Mahwah: Lawrence Erlbaum Associates.

Lane, R. D., Sechrest, L., Riedel, R. G., Weldon, V., Kaszniak, A. W., \& Schwartz, E. G. (1996). Impaired verbal and nonverbal emotion recognition in alexithymia. Psychosomatic Medicine, 58, 203-210.

McDougall, J. (1989). Theatres of the body: A psychoanalytic approach to psychosomatic illness. New York: Norton.

Montebarocci, O., Codispoti, M., Baldaro, B., \& Rossi, N. (2004). Adult attachment style and alexithymia. Personality and Individual Differences, 36, 499-507. http://dx.doi.org/10.1016/S0191-8869(03)00110-7

Morley, T. E., \& Moran, G. (2011). The origins of cognitive vulnerability in early childhood: Mechanisms linking early attachment to later depression Review Article. Clinical Psychology Review, 31, 1071-1082. http://dx.doi.org/10.1016/j.cpr.2011.06.006

Roque, L., \& Veríssimo, M. (2011). Emotional context, maternal behavior and emotion regulation. Infant Behavior and Development, 34, 617-626. http://dx.doi.org/10.1016/j.infbeh.2011.06.002

Rothbard, J. C., \& Shaver, P. R. (1994). Continuity of attachment across the life span. In M. B. Sperling, \& W. H. Berman (Eds.), Attachment in adults: Clinical and developmental perspectives. New York, London: The Guilford Press.

Sanderson, C. A., \& Evans, S. M. (2001). Seeing one's partner through intimacy-colored glasses: An examination of the process underlying the intimacy goals-relationship satisfaction link. Personality \& Social Psychology Bulletin, 27, 463-473. http://dx.doi.org/10.1177/0146167201274007

Sifneos, P. E. (2000). Alexithymia, clinical issues, politics and crime. Psychotherapy and Psychosomatics, 69, 113-116. http://dx.doi.org/10.1159/000012377

Taylor, G. J., \& Bagby, M. (2000). An overview of the alexithymia construct. In R. Bar-On, \& J. D. A. Parker (Eds.), The handbook of emotional intelligence (pp. 263-276). San Francisco: Jossey-Bass.

Waters, E. Merrick, S., Treboux, D., Crowell, J., \& Albersheim, L. (2000). Attachment security in infancy and early adulthood: A twenty-year longitudinal study. Child Development, 3, 684-689. http://dx.doi.org/10.1111/1467-8624.00176

Wilkie, J. R., Ferree, M. M., \& Ratcliff, K. S. (1998). Gender and fairness: Marital satisfaction in two-earner couples. Journal of Marriage and the Family, 60, 577-594. http://dx.doi.org/10.2307/353530 


\section{Copyrights}

Copyright for this article is retained by the author(s), with first publication rights granted to the journal.

This is an open-access article distributed under the terms and conditions of the Creative Commons Attribution license (http://creativecommons.org/licenses/by/3.0/). 